\title{
Tourism environmental impact along religious routes and slow transport infrastructures: the role of coastal areas
}

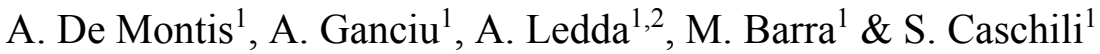 \\ ${ }^{1}$ Dipartimento di Agraria, University of Sassari, Italy \\ ${ }^{2}$ Dipartimento di Ingegneria Civile, Ambientale e Architettura, \\ University of Cagliari, Italy
}

\begin{abstract}
Tourism is a major sector of the European economy. In particular, religious tourism along pilgrimage routes is a prominent phenomenon. Some religious routes in the island of Sardinia, Italy, start from coastal zones and may exert a relevant impact over the environment. The aim of this paper is to analyse the environmental effects of Italian and Sardinian urban planning tools related with religious tourism. In particular, it focuses on SEA quality and integration with the European Tourism Indicators System (ETIS).

Keywords: SEA, ETIS, land use and transport planning.
\end{abstract}

\section{Introduction}

Pilgrimage routes are slow transport and mobility infrastructures that match the needs of typical contemporary religious tourists. Many times, periodic movements of pilgrims impact on local environmental resources. Despite many definitions, programmes, and regional strategies recall for a sustainable development of tourism, specific tools able to help decision makers to appreciate a correct tendency to tourism sustainability are still rare. In this respect, the European Commission through the Group on Sustainable Tourism (GST) drafted the "European Tourism Indicators System: for sustainable management at destination level" (ETIS). ETIS is conceived as an indicator based instrument able to assist in monitoring, managing, and improving the sustainability level of tourist destinations. While the adoption of ETIS is still voluntary, Strategic Environmental Assessment (SEA) is a mandatory process aiming at evaluating 
the impact of certain plans and programs over the environment (see, inter alia, the institutive Directive 2001/42 /EC). As SEA practice nowadays is steering professional behaviour toward virtuous paths, in this paper we aim at analysing some SEA processes of master plans approved in municipalities concerning four pilgrimage routes well known in Sardinia, Italy. In particular, we assess the level of adaptability of SEA monitoring indicators with respect to ETIS. The argument unfolds as follows. In the next section, we refer religious movements to the debate on sustainable tourism policies in Europe. In the third section, we recall some studies concerning SEA theory and quality assessment, while, in the fourth section, we present the fundamentals of ETIS. In section five, we present a three step methodology, which we apply to the case of Sardinia in section 6. In section 7 , we discuss the results obtained and wrap up the message of this paper with some conclusions and outlook remarks.

\section{Sustainable tourism policy in Europe}

According to [1], tourism is a relevant economic sector, as it is able to stimulate socio-economic growth particularly in rural and mountain areas, coastal regions and islands. The European Commission has long been committed to promoting sustainable development of tourism in Europe; tourism competitiveness is in fact linked to sustainability, as the attractiveness of a destination is clearly connected to its natural and cultural heritage and to the level of integration with local living communities [2].

Sustainable tourism means recognizing the limits and capacity of tourism resources. Sustainability can involve many aspects: i) responsible use of natural resources; ii) consideration of activities' impact on the environment; iii) use of "clean" energy; iv) protection of heritage, and preservation of natural and cultural tourist destinations; v) quality and durability of jobs created; vi) local economic impact. In this direction, strategic policies promoted by the European Commission aim at establishing or improving: i) a European tourism quality brand; ii) the European Charter for Sustainable Tourism; iii) a virtual observatory of tourism; iv) the accessibility of services; and v) the expertise in the sector. The relationship between tourism, transport, and the natural environment, and the need to preserve and enhance landscape have been stressed by many scholars [3] and public bodies at different administrative levels [4].

Globally, tourism is the economic sector that over the last ten years has had the strongest growth. In 2011, more than one billion people have travelled abroad for tourism. The European Union is the main tourist destination, and the tourism sector generates $10 \%$ of European GDP and includes $12 \%$ of the total workforce. In 2008, the European sites have attracted 370 million visitors, generating a 266 billion euro. Italy in the last decade has lost considerable tourist market share in favour of other European countries, traditionally competitors in such sector [4]. 


\section{Strategic environmental assessment: an overview}

As tourism, society, and environment are closely related $[5,6]$, tourism policies are territorial policies [7] representing a potential source of risk due to impacts on the environment $[8,9]$. In this respect, SEA is a mandatory procedure concerning the evaluation of the environmental effects of certain plans and programs [10]. In addition, SEA should not be considered as a mere evaluation tool but broadly as a decisional framework capable of indicating the most environmental friendly planning alternatives [11]. SEA is a useful operational tool for incorporating the sustainability concept and objectives within programming and planning processes. A successful SEA is characterised by broad and transparent public participation [12-16]. The Environmental Report (ER) is a key document, which shows a dynamic and participatory evaluation of the plan's effects on the environment. SEA develops in certain stages $[8,18]$ and the ER proposes, inter alia, the indicators able to support environmental monitoring [16-18].

According to recent bibliometric analyses [19], SEA effectiveness and, typically, ER quality emerge as major topics [3, 20, 21]. A number of studies develop on SEA quality appreciation [3, 10, 15, 20-30].

Table 1: $\quad$ SEA monitoring indicators: a general scheme.

\begin{tabular}{|l|l|}
\hline Macro component & Exemplary indicators \\
\hline 1. Air & PM10 concentration \\
\hline 2. Water & NHx concentration Organic (BOD) \\
\hline 3. Soil & Metal (As, Cd, Pb, Zn) concentration \\
\hline 4. Landscape & Number of historical or archaeological sites \\
\hline 5. Mobility & Extension of public mobility network \\
\hline
\end{tabular}

In Table 1, we report a general overview of the macro arguments leading the organization of SEA monitoring indicators. Environmental indicators are crucial and are selected during the design and construction of the scoping report, a document that is jointly discussed at the beginning of SEA process with the bodies with environmental responsibility, and further developed as a major element of the ER.

\section{ETIS: concept and application}

ETIS is an indicator based framework including 27 core and 40 optional indicators. Indicators are clustered into four sections: i) management and governance of tourism system; ii) economic capacity of the system; iii) socio- 
cultural aspects; and iv) natural environment [2]. Table 2 shows the ETIS indicators of the four sections.

Table 2: $\quad$ ETIS scheme of indicators by macro criteria, criteria and type.

\begin{tabular}{|c|c|c|c|}
\hline \multirow[t]{2}{*}{ Macro criteria } & \multirow[t]{2}{*}{ Criteria } & \multicolumn{2}{|c|}{ Indicator number by type } \\
\hline & & Main & Optional \\
\hline \multirow{4}{*}{ Management } & A.1 Sustainable Tourism Public Policy & 1 & 2 \\
\hline & $\begin{array}{l}\text { A.2 Sustainable Tourism Management } \\
\text { in Tourism Enterprises }\end{array}$ & 1 & 1 \\
\hline & A.3 Customer Satisfaction & 1 & 1 \\
\hline & A.4 Information and Communication & 1 & 1 \\
\hline \multirow{5}{*}{ Economics } & $\begin{array}{l}\text { B.1 Tourism Flow (volume and value) } \\
\text { at Destination }\end{array}$ & 2 & 3 \\
\hline & B. 2 Tourism Enterprise(s) Performance & 2 & 3 \\
\hline & B.3 Quantity and Quality of Employee & 1 & 2 \\
\hline & B.4 Safety and Healthy & 1 & 1 \\
\hline & B.5 Tourism Supply Chain & 1 & 2 \\
\hline \multirow{4}{*}{ Culture } & C.1 Community/Social Impact & 1 & 3 \\
\hline & C. 2 Gender Equality & 1 & 2 \\
\hline & C.3 Equality/Accessibility & 2 & 2 \\
\hline & $\begin{array}{l}\text { C.4 Protecting and Enhancing Cultural } \\
\text { Heritage, Local Identity and Assets }\end{array}$ & 1 & 2 \\
\hline \multirow{9}{*}{ Environment } & D.1 Reducing Transport Impact & 2 & 2 \\
\hline & D.2 Climate Change & 1 & 2 \\
\hline & D.3 Solid Waste Management & 2 & 1 \\
\hline & D.4 Sewage Treatment & 1 & 1 \\
\hline & D.5 Water Management & 1 & 3 \\
\hline & D.6 Energy Usage & 1 & 2 \\
\hline & $\begin{array}{l}\text { D.7 Landscape and Biodiversity } \\
\text { Management }\end{array}$ & 1 & 2 \\
\hline & D.8 Light and Noise Management & 1 & 1 \\
\hline & D.9 Bathing Water Quality & 1 & 1 \\
\hline
\end{tabular}

ETIS is a framework able to assist analysts while monitoring a regional system that supports a given tourism supply and is based on responsibility in decision making. 


\section{Methodology}

The methodology adopted in our case includes three steps, as indicated in Table 3. In the first phase, we understand the influence of pilgrimage routes acknowledged by the Autonomous Region of Sardinia through a selection of municipalities hosting part of those paths. Geographical analyses are developed in the GIS environment provided by an open source tool (QuantumGIS ${ }^{\circledR}$ ). In the second step, we check whether the municipalities selected in step 1 have adopted or approved a land use planning instrument including an SEA procedure. In the third step, we ascertain the level of adaptability to ETIS of the set of monitoring indicators referred to in the SEA report.

Table 3: The method adopted: steps and description.

\begin{tabular}{|l|l|}
\hline Step & Description \\
\hline 1. Geography & Selecting municipalities interested by pilgrimage routes \\
\hline 2. SEA & Choosing planning tools with SEA \\
\hline 3. Assessment & Comparing SEA monitoring indicators with ETIS \\
\hline
\end{tabular}

We are interested in investigating the adaptability between the SEA monitoring and the ETIS indicators. The level of adaptability is a sign of the suitability of SEA to appreciate the interference of a certain plan or program over local tourism supply under sustainability conditions.

In order to construct a measure of adaptability level, we use the index described in equation (1)

$$
A_{i, k}=\left(\frac{\sum_{1}^{n} s_{j}}{2 n}\right)_{i, k}
$$

where $A_{i, k}$ is the adaptability index, $i$ and $k$ indicate SEA report and ETIS macro criteria, $n$ represents the number of monitoring indicators classifiable in the ETIS macro criteria $k$ and included in the SEA report $i$, and $s_{j}$ is a discrete score representing the similarity level to ETIS indicators and defined according to Table 4.

Table 4: Similarity level: score, meaning, and calculation.

\begin{tabular}{|c|l|l|}
\hline Score & \multicolumn{1}{|c|}{ Meaning } & \multicolumn{1}{c|}{ Calculation } \\
\hline 0 & $\begin{array}{l}\text { The environmental indicator is not similar } \\
\text { to ETIS indicators }\end{array}$ & $\begin{array}{l}\text { No ETIS indicator is similar to } \\
\text { the monitoring indicator }\end{array}$ \\
\hline 1 & $\begin{array}{l}\text { The environmental indicator is moderately } \\
\text { similar to ETIS indicators }\end{array}$ & $\begin{array}{l}\text { One ETIS indicator is similar } \\
\text { to the monitoring indicator }\end{array}$ \\
2 & $\begin{array}{l}\text { The environmental indicator is fully } \\
\text { similar to ETIS indicators }\end{array}$ & $\begin{array}{l}\text { Two or more ETIS indicators } \\
\text { are similar to the monitoring } \\
\text { indicator }\end{array}$ \\
\hline
\end{tabular}




\section{A case study in Sardinia}

In this section we select some SEA reports approved by Sardinian municipalities, whose territory hosts at least one pilgrimage route. The Autonomous Region of Sardinia has launched the campaign "Cammini di Sardegna" [Routes of Sardinia] (http://www.camminidisardegna.it/cammini). "Cammini di Sardegna" focuses on four paths inspired to well-known saints: San Giorgio, Sant'Efisio, Santa Barbara, and Santu Jacu.

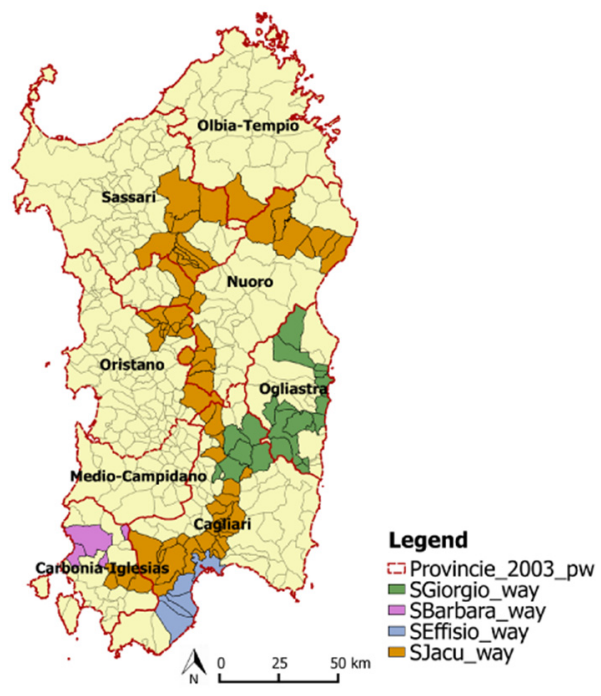

Figure 1: Municipalities crossed by religious routes in Sardinia.

We investigate on the number and major characteristics of the municipalities crossed by at least one pilgrimage route in Sardinia (see Figure 1). As a whole, religious paths attain 86 municipalities extending over a surface area equal to $5,676 \mathrm{~km}^{2}$ (roughly one fourth of the entire regional area). Resident population living in these municipalities amounts roughly to 500,000 people [31] corresponding to one-third of the entire regional figure.

In Table 5, we illustrate how the Santu Jacu route is the most important path of Sardinia. This path begins in the coastal city of Cagliari, reaches the most

Table 5: Pilgrimage routes relative extension with respect to the whole region.

\begin{tabular}{|l|c|c|c|}
\hline \multicolumn{1}{|c|}{ Name } & $\begin{array}{c}\text { Number of } \\
\text { municipalities involved }\end{array}$ & $\begin{array}{c}\text { Municipal surface } \\
\text { area extension }\end{array}$ & Resident population \\
\hline S Jacu & $16.71 \%$ & $16.46 \%$ & $24.02 \%$ \\
\hline S Giorgio & $4.77 \%$ & $5.07 \%$ & $2.55 \%$ \\
\hline S Efisio & $1.33 \%$ & $1.66 \%$ & $12.12 \%$ \\
\hline S Barbara & $0.53 \%$ & $1.06 \%$ & $2.04 \%$ \\
\hline
\end{tabular}


remote municipalities in province of Sassari and then ends in the province of Nuoro. In the second step, we study the status of master planning and related SEA processes developed by municipalities hosting pilgrimage routes. In Figure 2(a), we analyse master planning tools in the eighty-six communes interested. Sixty-three municipalities have approved a Municipal Urban Plan (Italian code PUC), which is currently the main land use and landscape planning instrument.

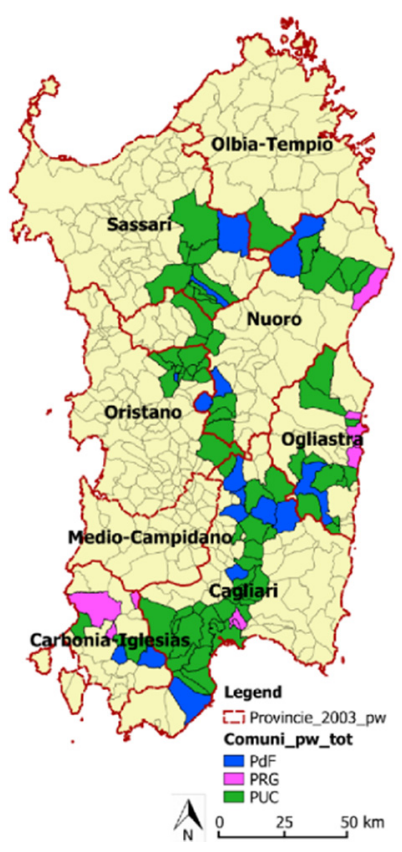

(a)

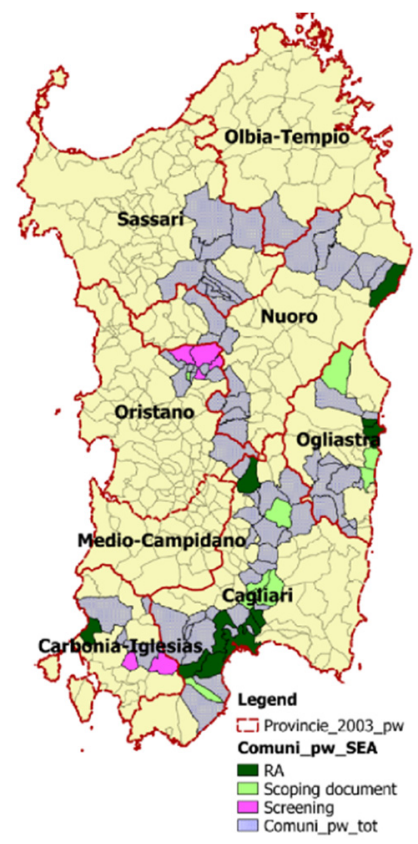

(b)

Figure 2: Master planning tools (a) and SEA processes (b) in municipalities hosting pilgrimage routes.

In Figure 2(b) and in Table 6, we illustrate an analysis of SEA processes. Fifteen communes have begun an SEA process, seven municipalities have completed the process, five are still at the scoping phase, and the last three municipalities have a plan under SEA screening. The coastal municipality of Cagliari is crossed by two paths: Sant'Efisio and Santu Jacu. All religious paths cross at least one municipality, where a PUC is in force and an SEA has been applied. We now focus on the assessment of the seven SEA ERs approved in the municipalities of Assemini, Cagliari, Capoterra, Girasole, Gonnesa, Irgoli, and Settimo San Pietro. In the case of Gonnesa, we have considered two sets of environmental indicators pertaining to two diverse planning instruments: the municipal land use plan (PUC) and the coastal land use plan (PUL). 
Table 6: Status of the SEA processes of planning instrument related to pilgrimage routes.

\begin{tabular}{|l|l|l|}
\hline \multicolumn{1}{|c|}{ Municipality } & \multicolumn{1}{c|}{ SEA status } & \multicolumn{1}{c|}{ Route } \\
\hline Aidomaggiore & Screening & Santu Jacu \\
\hline Assemini & ER & Santu Jacu \\
\hline Cagliari PUL & ER & Sant'Efisio; Santu Jacu \\
\hline Capoterra & ER & Sant'Efisio \\
\hline Cardedu & Scoping document & San Giorgio \\
\hline Dolianova & Scoping document & Santu Jacu \\
\hline Girasole & ER & San Giorgio \\
\hline Gonnesa & ER & Santa Barbara \\
\hline Gonnesa PUL & ER & Santa Barbara \\
\hline Irgoli & ER & Santu Jacu \\
\hline Sedilo & Screening & Santu Jacu \\
\hline Serdiana & Scoping document & Santu Jacu \\
\hline Settimo S.Pietro & ER & Santu Jacu \\
\hline Sorradile & Screening & Santu Jacu \\
\hline Villa S.Pietro & Scoping document & Sant'Efisio \\
\hline Urzulei & Scoping document & San Giorgio \\
\hline
\end{tabular}

In the third step, we assess the adaptability index described in equation (1) for the eight SEA indicator systems described above. In Table 7, for each SEA report, we report the values obtained for $A_{i, k}$ concerning the general adaptability to the entire set the four criteria clusters of ETIS.

Table 7: Adaptability index analysis versus the entire set and the four clusters of ETIS criteria.

\begin{tabular}{|l|c|c|c|c|c|}
\hline Municipalities & \multicolumn{5}{|c|}{ Adaptability index } \\
\hline & Entire ETIS & \multicolumn{4}{|c|}{ ETIS criteria } \\
\hline & & Management & Economic & Cultural & Environmental \\
\hline Assemini & $43.53 \%$ & $62.50 \%$ & $100.00 \%$ & $78.57 \%$ & $78.79 \%$ \\
\hline Cagliari PUL & $55.56 \%$ & $25.00 \%$ & $100.00 \%$ & $0.00 \%$ & $60.00 \%$ \\
\hline Capoterra & $30.63 \%$ & $75.00 \%$ & $0.00 \%$ & $62.50 \%$ & $72.62 \%$ \\
\hline Girasole & $63.33 \%$ & $0.00 \%$ & $100.00 \%$ & $50.00 \%$ & $93.75 \%$ \\
\hline Gonnesa PUC & $49.31 \%$ & $100.00 \%$ & $50.00 \%$ & $87.50 \%$ & $76.56 \%$ \\
\hline Gonnesa PUL & $50.00 \%$ & $100.00 \%$ & $100.00 \%$ & $0.00 \%$ & $85.00 \%$ \\
\hline Irgoli & $37.33 \%$ & $100.00 \%$ & $0.00 \%$ & $83.33 \%$ & $94.23 \%$ \\
\hline $\begin{array}{l}\text { Settimo San } \\
\text { Pietro }\end{array}$ & $50.00 \%$ & $100.00 \%$ & $0.00 \%$ & $58.33 \%$ & $72.34 \%$ \\
\hline Average values & $47.46 \%$ & $70.31 \%$ & $56.25 \%$ & $52.53 \%$ & $79.16 \%$ \\
\hline
\end{tabular}


The analysis of the average values points out a moderate adaptability $(47.46 \%)$ of the set of indicators included in the SEA reports investigated in this study with respect to the entire set of ETIS indicators. With reference to the ETIS criteria, on average the adaptability index scores very well for the Environmental criteria (79.16\%). This outcome confirms the evidence that SEA report indicators are designed first of all to capture environmental issues.

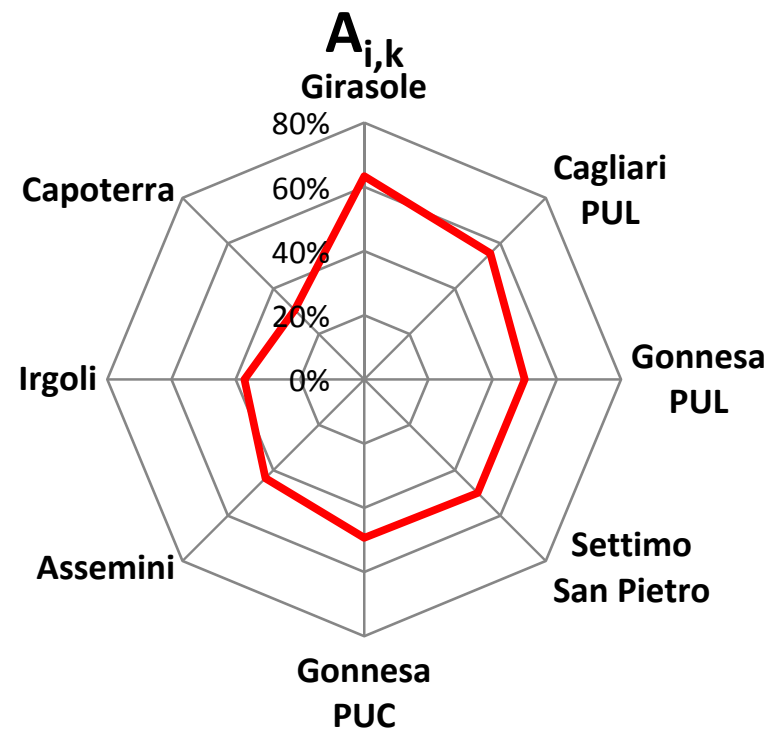

Figure 3: Spider graph of the adaptability index with respect to the entire set of ETIS indicators.

Figure 3 shows the detail of the adaptability index for each set of indicators scrutinized. The highest values are calculated for the SEA reports approved by municipalities located near the coastline and, thus, interested by tourist development. The adaptability index referred to the ETIS criteria environment is remarkable for Girasole (93.75\%) and Irgoli (94.23\%), while reaches lowest figure for Capoterra $(72.62 \%)$. The adaptability index referred to the ETIS criteria Economic and Culture shows fairly lower average values (respectively, $56.25 \%$ and $52.53 \%$ ). With respect to the first criteria, the index displays a very volatile trend with values ranging from zero to a hundred percent.

\section{Discussion and conclusions}

In this paper, we have scrutinized the status of SEA developed by municipalities interested by religious routes in order to ascertain the level of adaptability of eight selected SEA reports to the principles of ETIS, a system of indicators designed by the European Commission to appreciate the quality of tourism 
supply. We discuss the meaning of the results and propose possible future research studies.

With the exception of the coastal land use plan of Cagliari and Gonnesa, the remaining planning instruments do not focus specifically on tourism and generally do not include indicators able to describe tourist characteristics. They are instruments designed to plan the general effects of municipal development on land use pattern.

The analysis of the adaptability index reports on a moderate average ETISadaptability of the indicator systems included in the SEA reports considered in this study. This means that at the moment much work has to be done in the direction of a reasonable ability to describe tourism systems. Generally, SEA reports include indicator systems that are very well adaptable to the ETIS indicators included in the Environmental criteria.

Indicators such as number of jobs or bed places in hotels are included only in three cases (Cagliari, Girasole, and Gonnesa PUL). SEA reports often times do not include indicators of social mobility, gender equity, or accessibility.

ETIS has been designed to monitor the effects of tourism throughout Europe and refers to the impacts connected to an expansion of tourism movements. Sardinia is a well know destination, where tourism still evolves according to seasonal and traditional (i.e. sun-sand-sea driven) patterns, though. This may be one of the reasons why land use general planning instruments do not pay a sufficient attention to that important phenomenon. The analysis developed in this study confirms this concept, as often SEA reports approved in coastal municipalities include indicator systems that are more adaptable to ETIS.

\section{Acknowledgement}

This work is supported by funds received from the Autonomous Region of Sardinia through the research project "Efficacia ed efficienza della governance paesaggistica e territoriale in Sardegna: il ruolo della VAS e delle IDT" [Efficacy and efficiency of the landscape and environmental governance in Sardinia: the role of SEA and of SDI].

\section{References}

[1] European Commission (2010), L'Europa, prima destinazione turistica mondiale - un nuovo quadro politico per il turismo europeo; $\operatorname{COM}(2010) / 352$, Bruxelles, 30.6.2010.

[2] European Commission (2013), Il Sistema europeo di indicatori per il turismo. ISBN 978-92-79-29342-9, doi:10.2769/47214.

[3] De Montis A., Ganciu A., Ledda A., Barra M., Caschili S., Puddu F., Paoli F. (2014a), Analisi comparata della VAS nei piani regionali di trasporto e logistica: stato di fatto e indicazioni per la progettazione; XXXV Conferenza italiana di scienze regionali - Padova. 
[4] Repubblica Italiana (2013), Ministero per gli Affari Regionali - il Turismo e lo Sport; Piano Strategico Per Lo Sviluppo Del Turismo In Italia Turismo Italia 2020; ROMA - 18 gennaio 2013.

[5] Urry, J. (2001). The tourist gaze, Sage, London.

[6] WTO-ETC (2005). City tourism \& culture. The European experience, Madrid.

[7] Gemmiti R., (2011), Politiche territoriali e politiche turistiche nell'evoluzione urbana. Riflessioni intorno a Roma; Università di Roma, Sapienza, MEMOTEF - Dip. di Metodi e Modelli per l'Economia e il Territorio e la Finanza, Working paper 87/2011.

[8] Sheate W.R. (1992), Strategic Environmental Assessment in the Transport Sector, Project Appraisal, 7, 3: 170-174.

[9] Tomlinson P. (2011), SEA and Transport Planning. In: Sadler B., Dusik J., Fischer T.B., Partidário M.R., Verheem R., Aschemann R. (eds.), Handbook of Strategic Environmental Assessment. London: Earthscan. 177-189.

[10] Sadler B., Aschemann R., Dusik J., Fischer T.B., Partidário M., Verheem R. (2011), Handbook of strategic environmental assessment. New York: Earthscan Publications.

[11] Codice di edilizia e urbanistica (2013), Utet Giuridica, ISBN 10: 8859809150 / ISBN 13: 9788859809159.

[12] Gauthier M., Simard L., Waau J.P. (2011), Public participation in strategic environmental assessment (SEA): Critical review and the Quebec (Canada) approach, Environmental Impact Assessment Review, 31, 1: 4860.

[13] van Buuren A., Nooteboom S. (2010), The Success of SEA in the Dutch Planning Practice. How Formal Assessments Can Contribute to Collaborative Governance, Environmental Impact Assessment Review, 30, 2: $127-135$.

[14] IAIA (2002), Strategic environmental assessment performance criteria, IAIA special publication series, n. 1, International Association for Impact Assessment. Fargo: USA.

[15] Fischer T.B., Gazzola P. (2006), SEA Effectiveness Criteria - Equally Valid in All Countries? The Case of Italy, Environmental Impact Assessment Review, 26, 4: 396-409.

[16] Corpade A.M., Corpade C., Petrea D., Moldovon C. (2012), Integrating Environmental Considerations into Transportation Planning through Strategic Environmental Assessment; Journal of Settlements and Spatial Planning, 3, 2: 115-120.

[17] Brokking P., Schmidtbauer J.C., Eriksson I.M., Balfors B. (2004), SEA in Swedish Transportation Policy-Making and Planning - Political Ambition and Practice, European Environment, 14, 2: 94-104.

[18] Diamantini C., Geneletti D. (2004), Reviewing the Application of SEA Sectoral Plans in Italy. The Case of the Mobility Plans of an Alpine Region, European Environment, 14, 2: 123-133. 
[19] Caschili S., De Montis A., Ganciu A., Ledda A., Barra M. (2014), The Strategic Environment Assessment Bibliographic Network: A Quantitative Literature Review Analysis. Environmental Impact Assessment Review, 47: 14-28, ISSN: 0195-9255, doi: 10.1016/j.eiar.2014.03.003.

[20] De Montis A., Ledda A., Caschili S., Ganciu A., Barra M. (2014b), SEA Effectiveness for Landscape and Master Planning: An Investigation in Sardinia, Environmental Impact Assessment Review, 47: 1-13.

[21] Bonde J., Cherp A. (2000), Quality Review Package for Strategic Environmental Assessments of Land-Use Plans, Impact Assessment and Project Appraisal, 18, 2: 99-110.

[22] De Montis A. (2013), Implementing Strategic Environmental Assessment of Spatial Planning Tools. A Study on the Italian Provinces, Environmental Impact Assessment Review, 41: 53-63.

[23] Fischer T.B. (2007), Theory and Practice of Strategic Environmental Assessment. Towards a More Systematic Approach. London: Earthscan Press.

[24] Fischer T.B. (2010), Reviewing the Quality of Strategic Environmental Assessment Reports for English Spatial Plan Core Strategies, Environmental Impact Assessment Review, 30, 1: 62-69.

[25] Fischer T.B. (2012), The Quality of Local Transport Plan (LTP) 3 SEA Reports in North West England - A Comparative Review with English Spatial and Waste Management Planning Related SEA Practice, Town and Country Planning, 81, 6: 281- 286.

[26] Fischer T.B., Potter K., Donaldson S., Scott T. (2011), Municipal Waste Management Strategies, Strategic Environmental Assessment and the Consideration of Climate Change in England, Journal of Environmental Assessment Policy and Management, 13, 4: 541-565.

[27] Jiricka A., Pröbstl U. (2008), SEA in Local Land Use Planning — First Experience in the Alpine States, Environmental Impact Assessment Review, 28, 4-5: 328-337.

[28] Noble B.F. (2009), Promise and Dismay: The State of Strategic Environmental Assessment Systems and Practices in Canada, Environmental Impact Assessment Review, 29, 1: 66-75.

[29] Retief F. (2007), A Performance Evaluation of Strategic Environmental Assessment (SEA) Processes Within the South African Context, Environmental Impact Assessment Review, 27, 1: 84-100.

[30] De Montis A. (2014), Strategic Environmental Assessment of Energy Planning Tools. A Study of Italian Regions and Provinces, Environmental Impact Assessment Review, 46: 32-42.

[31] Statistiche Sardegna. http://www.comuni-italiani.it/ (accessed March, 10 2015). 